\title{
Bond strength and adhesive remnant index of experimental brackets bonded with self-adhesive resin cement
}

\author{
Mateus Rodrigues-Tonetto1', Edson Alves de Campos², Eduardo Fernández ${ }^{3 *}$, \\ Milton Carlos Kuga ${ }^{2}$, Marcelo Ferrarezi de Andrade ${ }^{2}$, Mateus Coelho-Bandéca ${ }^{4}$
}

1 University of Cuiabá-UNIC, Cuiabá, MT - Brazil. 2 Department of Restorative Dentistry, UNESP, Univ Estadual Paulista, Araraquara, SP - Brazil.

3 School of Dentistry, University of Chile, Santiago-Chile. 4 CEUMA University, São Luis, MA - Brazil.

* Correspondence to: Eduardo Fernández G. $D D S, D S, P h D \mid$ Department of Restorative Dentistry, Universidad de Chile, Dental school | Sergio Livingstone Pohlhammer 943, Independencia |

Phone-Fax:+56229462929 - edofdez@yahoo.com | Santiago, Chile.

Trabajo recibido el 21/06/2016. Aprobado para su publicación el 26/11/2016

\section{ABSTRACT}

Aim: To evaluate the shear bond strength (SBS) and adhesive remnant index (ARI) of experimental brackets bonded with self-adhesive resin cement. Ninety bovine teeth were randomly distributed $(n=15)$ according to the groups: $\mathrm{G} 1$ - metal brackets bonded with Transbond ${ }^{\mathrm{TM}} \mathrm{XT}$; G2 - APC metal brackets bonded without additional adhesive system; G3 - APC metal brackets bonded with self-etching adhesive system; G4 - metal brackets bonded with RelyXU200; G5 - experimental brackets bonded with Transbond ${ }^{\mathrm{TM}}$ XT; G6 - experimental brackets bonded with RelyXU200. Shear bond strength test of the brackets was carried out and after their removal, the ARI was observed.

Results: The highest mean value of SBS was found in group 1 (14.33 MPa) and lower mean SBS has been in group $4(2.36 \mathrm{MPa})$. The mean values of SBS found in the experimental groups were higher compared to the non-modified brackets. The ARI analysis demonstrated that groups that received the phosphoric acid or selfetching primer (G1,G2,G3andG5) showed adhesive partially and fully adhered to the tooth. Greater amounts of remnants were adhered to the bracket in the experimental brackets, this minimizes the risk of damage to the tooth enamel since it requires minimal finishing. These results suggest that the experimental brackets are interesting options for future use in orthodontics, since it has sufficient adhesive strength to the orthodontic treatment, and less risk of damage to the enamel at the time of removal of the brackets, and is a simple and inexpensive alternative.

KEY WORDS

Brackets; Dental cements; Shear strength.

Rev. Clin. Periodoncia Implantol. Rehabil. Oral Vol. 10(2); 115-117, 2017.

\section{INTRODUCTION}

The bonding of brackets represents one of the most significant challenge in the assembly of orthodontic devices ${ }^{(9)}$. The development of new techniques for bracket bonding brought significant changes in clinical orthodontics, representing technical simplification and less chairside time ${ }^{(7)}$. This procedure has advantages compared to conventional banding presenting more aesthetic, less discomfort, more precise positioning, simplicity, speed, and ease of cleaning ${ }^{(7)}$.

Although bonding has various advantages for both the patient and dentist, the adhesive procedure is a sensitive technique. The resins have become the most used material by orthodontists for bracket bonding since adhesion has been proved in several studies ${ }^{(1,24)}$.

The main difference from the traditional composites in comparison to orthodontic composites is the filler percentage and size particles. Orthodontic resins have a lower amount of filler particles, which allows higher J Appl Oral Sci.e bond strength of experimental brackets bonded with self-adhesive resin cement on tooth enamel.

\section{MATERIALS AND METHODS}

\section{Specimens preparation}

Ninety bovine teeth were selected, cleaned and stored in thymol solution $(0.1 \%)$ no longer than two months until the time of use. The roots were cut and the teeth were embedded in chemically activated acrylic resin (Vipi Flash, DentalVipi, Pirassununga, Brazil) into cylindrical PVC (Tigre, Brazil) with a $20 \mathrm{~mm}$ internal diameter and height. Buccal portion of the specimen was parallel to a flat surface.

Prophylaxis was performed with rubber cup, pumice (SS White, Petrópolis, Brazil) and water for 10 seconds, followed by washing and drying at the same time with a triple syringe.

The teeth were randomly assigned $(n=15)$ according to the groups described in table1.

\section{Experimental brackets}

Modification of the bracket base was performed from traditional metal brackets (Victory Series ${ }^{\mathrm{TM}} 3 \mathrm{M}$ Unitek) in which the metal mesh
Table 1. Experimental groups.

\begin{tabular}{c|cc|}
\hline GROUPS & BRACKET & ADHESIVE PROCEDURE \\
\hline G1 & Traditional Metallic* $^{*}$ & Total etch adhesive system ${ }^{* *}$ \\
G2 & APC System & None \\
G3 & APC System & Self-etching adhesive system \\
G4 & Traditional Metallic $^{* *}$ & Self-adhesive resin cement \\
G5 & Modified $^{* * * * *}$ & Total etch adhesive system \\
G* \\
G6 & Modified $^{* * * * * *}$ & Self-adhesive resin cement \\
\end{tabular}

${ }^{*} V_{i c t o r y}{ }^{\mathrm{TM}}$ series $3 \mathrm{M}$ Unitek, Monrovia, Calif, USA ${ }^{* *}$ Transbond ${ }^{\mathrm{TM}}$ XT, 3M Unitek, Monrovia, Calif, USA ${ }^{* * *}$ APC System, 3M Unitek, Monrovia, Calif, USA

${ }^{* * * *}$ Transbond ${ }^{\mathrm{TM}}$ Plus Self-Etching Primer, 3M Unitek, Monrovia, Calif, USA

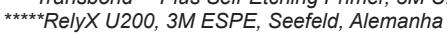

${ }^{* * * * * \star}$ Alteration in the base of the bracket Victory ${ }^{\mathrm{TM}}$ series $3 \mathrm{M}$ Unitek, Monrovia, Calif, USA

was altered. Composite resin Z 350XT (3M ESPE тM) was evenly placed over the mesh with a single increment to fill the space in the fabric, making a smooth and uniform base. Then, the composite base was polymerized during 20 seconds (Radii Plus - SDI). This modification allows the self-adhesive resin cement to be placed in contact with the base composite and tooth enamel since the self-adhesive resin cement in contact with the bracket metal mesh proved to be inefficient ${ }^{(3,9)}$. This modification on the bracket is necessary for possible improvement in the values of union.

Adhesive procedure

Group 01

Bovine enamel was conditioned for 30 seconds with $37 \%$ phosphoric acid on the buccal surface center, with the conditioning area corresponding to the bracket base area. And after 30 seconds, 
the acid was washed with water and dried for 15 seconds. Transbond XT primer followed by a single 2 seconds air jet were applied to the etched surface and the metal bracket was (Victory Series ${ }^{\mathrm{TM}} 3 \mathrm{M}$ Unitek) bonded with Transbond TM XT (3M Unitek, Monrovia, Calif, USA).

Group 02

No additional adhesive procedure was performed. The brackets were bonded with the APC's system composite (3M Unitek, Monrovia, Calif, USA).

Group 03

Transbond $^{\mathrm{TM}}$ Plus Self-Etching Primer was applied actively for 5 seconds on the labial surface of the enamel, a single air jet was applied for two seconds and the APC brackets was bonded (3M Unitek, Monrovia, Calif, USA).

Group 04

No prior treatment was performed on enamel. The resin cement RelyX U100 self-adhesive (3M ESPE, Seefeld, Germany) was manipulated and applied only to the area corresponding to the bracket base and the metal brackets Victory ${ }^{\mathrm{TM}}$ (3M Unitek, Monrovia, Calif., USA) were bonded.

Group 05

The same procedure was carried out in group 01 .

Group 06

The same procedure was carried out in the group 04 .

\section{Brackets bonding}

Central incisor brackets according to each group were used and were positioned on the tooth buccal surface with the aid of grasping forceps for bonding (Ortoply, Philadelphia, USA). All bonding procedures were performed by the same calibrated to procedure operator. After positioning the bracket, it was pressed against the tooth enamel in order to decrease the thickness of the composite between the bracket and the enamel. Excess composite was removed respecting the external limits of the bracket base and the polymerization was carried out for 10 seconds on each side (mesial, distal, incisal and gingival) with the unit LED (Radii-plus, SDI, Au) with $1100 \mathrm{~mW} / \mathrm{cm}^{2}$. The polymerization was performed with the light tip positioned $2 \mathrm{~mm}$ distant from the surface of the specimen.

\section{Shear bond strength}

Shear bond strength test of the brackets was performed in the universal testing machine (EMIC - DL 2000, São José dos Pinhais, Brazil), regulated to a compression speed of $0.5 \mathrm{~mm} / \mathrm{min}$. The cylinder containing the acrylic resin tooth was placed on the lower jaw of the machine and the bracket base was parallel to shear force direction according to protocol.

The values of SBS were recorded in $\mathrm{kgf}$ and transformed in $\mathrm{kgf} /$ $\mathrm{cm}^{2}$, using the following formula:

$E=\operatorname{Kgf} A$

$\mathrm{E}=$ Mechanical Tests

$\mathrm{Kgf}=$ Strength needed to remove the bracket

$A=$ Bracket area

Subsequently, the values of SBS in $\mathrm{kgf} / \mathrm{cm}^{2}$ were converted into MPa.

Adhesive remnant index (ARI) adhered to the tooth after bracket debonding

After brackets removal, the ARI was observed in a stereomicroscope (Carl Zeiss, Brazil) by and blinded and calibrated to procedure examiner, with $30 \mathrm{X}$ of magnification. The amount of adhesive material in the enamel after debonding was evaluated according to the scores proposed by Artun \& Bergland (1984)3: Score 0 - no adhesive in the tooth; score 1 - less than half the adhesive left in the tooth; score 2 - more than half of the adhesive left in the tooth; and score 3 - all adhesive was present in the tooth.

\section{RESULTS}

Table 2 presents the results of the SBS test. Higher values of SBS were found in groups $1(20.60 \mathrm{MPa})$ and $3(20.59 \mathrm{MPa})$. The lowest resistance was found in group $4(0.98 \mathrm{MPa})$. Group 1 had the highest average $(14,33 \mathrm{MPa})$ and group 4 the lowest $(2.36 \mathrm{MPa})$. Data were subjected to one-way analysis of variance - ANOVA followed by Tukey post-test $(p=0.05)$ (Table 1$)$.

Tukey test showed that groups 2 and 4 were similar, presenting statistically lower values of SBS. Group 6 showed a statistically significant difference from group 4, with the highest average. Group 1 had higher mean values and statistically significant difference in all groups.

By analyzing the ARI on dental enamel the frequency of scores was evaluated and it could be seen that groups 4 and 6 do not showed
Table 2. Description of the mean, standard deviation, minimum, maximum, and a confidence interval of $95 \%$ expressed in MPa of the groups submitted to SBS

\begin{tabular}{|c|c|c|c|c|c|}
\hline GROUP & MEAN & S.D & MINIMUM & MAXIMUM & $\begin{array}{c}\text { 95\% C. I. } \\
\text { (MIN; MAX) }\end{array}$ \\
\hline 1 & 14,33 & 4,01 & 8,76 & 20,60 & 12,$11 ; 16,56$ \\
\hline 2 & 4,78 & 1,95 & 2,15 & 8,64 & 3,$69 ; 5,86$ \\
\hline 3 & 10,46 & 4,18 & 4,57 & 20,59 & 8,$14 ; 12,78$ \\
\hline 4 & 2,36 & 0,79 & 0,98 & 3,45 & 1,$92 ; 2,80$ \\
\hline 5 & 9,99 & 1,94 & 7,20 & 13,41 & 8,$92 ; 11,08$ \\
\hline 6 & 5,33 & 1,22 & 3,12 & 7,53 & 4,$65 ; 6,01$ \\
\hline
\end{tabular}

Table 3. ARI was evaluated according Artun and Bergland (1984) and the frequency of the appearance of scores were analyzed in each group.

\begin{tabular}{|c|c|c|c|c|}
\hline \multirow{2}{*}{ GROUP } & \multicolumn{5}{|c|}{ SCORE } \\
\cline { 2 - 5 } & $\mathbf{0}$ & $\mathbf{1}$ & $\mathbf{2}$ & $\mathbf{3}$ \\
\hline 1 & 0 & 6 & 7 & 2 \\
2 & 2 & 7 & 3 & 3 \\
3 & 1 & 5 & 6 & 3 \\
4 & 4 & 11 & 0 & 0 \\
5 & 1 & 6 & 5 & 3 \\
6 & 1 & 14 & 0 & 0 \\
\hline
\end{tabular}

Score 0 - no amount of adhesive left in the tooth; score 1 - less than half the adhesive left in the tooth; score 2 - more than half of the adhesive left in the tooth; and score 3 - all adhesive adhered to the tooth.

scores 2 and 3, where more material was bonded to the tooth. However, the group that used the phosphoric acid or self-etching primer (groups $1,2,3$ and 5) showed adhesive partially and fully adhered to the tooth (Table 3).

\section{DISCUSSION}

The self-adhesive resin cement consists of modified monomers in methacrylate phosphoric acid that forms cross-links in cement matrix during the polymerization process ${ }^{(20)}$. Whereas the phosphoric acid contributes to the self-adhesion, double carbon bonds cause a high reactivity of methacrylate monomers with each other. Thus, the cement shows a high degree of monomer particles interrelated and good mechanical properties of this cement can be achieved even without pretreatment of the dental substrate ${ }^{(20)}$.

The literature reports that most of the remaining cement after debonding is located in the bracket interface ${ }^{(2)}$. This is due to incomplete polymerization of the cement below the base of the metal substrate, because the light is not able to reach the cement behind the bracket metal mesh ${ }^{(22)}$. In an attempt to improve the values of SBS of metal brackets bonded with self-adhesive cement, a project to redesign the bracket base was developed.

The innovative design of the metal bracket base consists of a thin layer of multifunctional methacrylate derivative of Bis-GMA. In our study, this experimental brackets bonded with self-adhesive cement (G6) had a significantly higher mean SBS compared with the metal brackets bonded with the same cement (G4). However, the SBS values were lower than metal brackets bonded with Transbond XT (G1). In addition, SBS of brackets bonded with self-adhesive cement (G4) were insufficient for bonding orthodontic brackets successfully. Low values found in experimental brackets can be explained by the fact that alterations were hand made and some details at the base of the brackets could be improved. Furthermore, the experimental brackets had better results than metal base brackets bonded with selfadhesive cement.

Traditional adhesive systems used for bonding orthodontic brackets depends of acid etching for better retention ${ }^{(15,19,25)}$. Although traditional adhesives are widely used, methods to simplify bonding procedures have been reported in the literature, most of which derived from the self-adhesive cements ${ }^{(19,25)}$.

Self-adhesive resin cements are used for luting crowns, inlays, onlays and fixed partial dentures ${ }^{(8,11,13,29)}$. The use of these materials simplifies the bonding procedure because it reduces the number of 
adhesion steps. RelyX Unicem was the first product from the class of self-adhesive cement to be introduced on the market and is the most tested material. It contains multifunctional monomers with phosphoric acid groups which simultaneously demineralize and infiltrate adhesive monomers in the enamel and dentin ${ }^{(8,11)}$

Vincent et al. ${ }^{(29)}$ reported that RelyX Unicem has less SBS values than conventional adhesive system after storage of the samples in water for 24 hours at $37^{\circ} \mathrm{C}$. However, the SBS values were clinically sufficient to support the activation device. Moreover, Bishara et al..$^{(4)}$ and Al-Saleh \& El-Mowafy ${ }^{(2)}$ found that the SBS of metal brackets bonded with self-adhesive resin cement was insufficient for bonding orthodontic brackets successfully.

The magnitude of the bond strength clinically necessary to support orthodontic treatment without the occurrence of failure is difficult to measure. Literature reports that strength between 5.9 and $8 \mathrm{MPa}$ are sufficient to satisfy the clinical requirement ${ }^{(10,23)}$.

\section{CONCLUSION}

The results showed that the means values of SBS values found in the experimental brackets groups were higher compared to the ones that were not modified. Also, in experimental brackets a larger amoun of adhesive remnants were adhered to the bracket base, minimizing the risk of damage to the tooth enamel since it would require minimal finishing. These results suggest that the experimental brackets are interesting options for future use in orthodontics.

\section{ETHICAL CONSIDERATIONS}

This in vitro work does not require ethics committee And the authors declare no conflicts of interest

\section{References}

1. Abdelnaby YL, Al-Wakeel Eel S. Effect of early orthodontic force on shear bond strength of orthodontic brackets bonded with different adhesive systems. Am J Orthod Dentofacial Orthop. 2010;138(2):208-214.

2. Al-Saleh M, El-Mowafy O. Bond strength of orthodontic brackets with new selfadhesive resin cements. Am J Orthod Dentofacial Orthop. 2010;137:528-533.

3. Artun J, Bergland S. Clinical trials with crystal growth conditioning as an alternative to acid-etch enamel pretreatment. Am J Orthod. 1984;85: 333-340.

4. Bishara SE, Ajlouni R, Laffoon JF, Warren JJ. Comparison of shear bond strength of two self-etch primer/adhesive systems. Angle Orthod. 2006; 76:123-126.

5. Boncuk Y, Cehreli ZC, Polat-Ozsoy O. Effects of different orthodontic adhesives and resin removal techniques on enamel color alteration. Angle Orthod. 2014;84(4):634641.

6. Braga RR, Hilton TJ, Ferracane JL. Contraction stress of flowable composite materials and their efficacy as stress-relieving layers. J Am Dent Assoc. 2003;134(6):721-728.

7. Castilla AE, Crowe JJ, Moses JR, Wang M, Ferracane JL, Covell Jr DA Measurement and comparison of bracket transfer accuracy of five indirect bonding techniques. Angle Orthod. 2014;84(4):607-614.

8. Chieffi N, Chersoni S, Papacchini F, Vano M, Goracci C, Davidson CL, Tay FR, Ferrari M. The effect of application sustained seating pressure on adhesive luting procedure. Dent Mater. 2007;23:159-164.

9. Correr Sobrinho L, Correr GM, Consani S, Sinhoreti MA, Consani RL. Influence of post-fixation time on shear bond strength of brackets fixed with different materials. Pesqui Odontol Bras. 2002;16:43-49.

10. Damon PL, Bishara SE, Olsen ME, Jakobsen JR. Bond strength following the application of chlorhexidine on etched enamel. Angle Orthod. 1997;67:169-172.

11. D'Arcangelo C, Cinelli, M, De Angelis F, D'Amario M. The effect of resin cement film thickness on the pullout strength of a fiber-reinforced post system. J Prosthet Dent. 2007:98:193-198.

12. D'Attilio M, Traini T, Di lorio D, Varvara G, Festa F, Tecco S. Shear bond strength, bond failure, and scanning electron microscopy analysis of a new flowable com-posite for orthodontic use. Angle Orthod. 2005;75(3):410-415.

13. Faria-e-Silva AL, Pedrosa-Filho CDF, Menezes MDS, Silveira DMD, Martins LRM. Effect of relining on fiber post retention to root canal. J Appl Oral Sci. 2009:17:604. 14. Ferracane JL, Stansbury JW, Burke FJ. Self-adhesive resin cements - chemistry, properties and clinical considerations. J Oral Rehabil. 2011;38: 295-314.
15. Finnema KJ, Ozcan M, Post WJ, Ren Y, Dijkstra PU. In-vitro orthodontic bond strength testing: a systematic review and meta-analysis. Am J Orthod Dentofacial Orthop. 2010;137:615-622.

16. Frankenberger $R$, Lopes $M$, Perdigao J, Ambrose WW, Rosa BT. The use of flowable composites as filled adhesives. Dent Mater. 2002;18(3):227-238.

17. Hirani S, Sherriff M. Bonding characteristics of a self-etching primer and precoated brackets: an in vitro study. Eur J Orthod. 2006;28: 400-404.

18. Ireland AJ, Sherriff M. Use of an adhesive resin for bonding orthodontic brackets. Eur J Orthod. 1994;16(1):27-34

19. Bishara SE, Ajlouni R, Laffoon JF, Warren JJ. Comparison of shear bond strength of two self-etch primer/adhesive systems. Angle Orthod. 2006;76:123-126.

20. Radovic I, Monticelli F, Goracci C, Vulicevic ZR, Ferrari M. Self-adhesive resin cements: a literature review. J Adhes Dent. 2008;10: 251-258.

21. Rajagopal R, Padmanabhan S, Gnanamani J. A comparison of shear bond strength and debonding characteristics of conventional, moisture-insensitive, and selfetching primers in vitro. Angle Orthod. 2004;74(2):264-268.

22. Ramesh Kumar KR, Shanta Sundari KK, Venkatesan A, Chandrasekar S. Depth of resin penetration into enamel with 3 types of enamel conditioning methods: a confocal microscopic study. Am J Orthod Dentofacial Orthop. 2011;140:479-485.

23. Reynolds IR. Letter: Composite filling materials as adhesives in orthodontics. $\mathrm{Br}$ Dent J. 1975;138:183.

24. Reynolds IR. A review of direct orthodontic bonding. Br J Orthod. 1975;2:171-178

25. Scougall Vilchis RJ, Yamamoto S, Kitai N, Yamamoto K. Shear bond strength of orthodontic braquetes bonded with different self-etching adhesives. Am J Orthod Dentofacial Orthop. 2009;136:425-430.

26. Senawongse P, Sattabanasuk V, Shimada Y, Otsuki M, Tagami J. Bond strength of current adhesive systems on intact and ground enamel. J Esthet Restor Dent. 2004;16(2):107-115

27. Uysal T, Ulker M, Ramoglu SI, Ertas H. Microleakage under metallic and ceramic brackets bonded with orthodontic self-etching primer systems. Angle Orthod. 2008;78(6):1089-1094

28. Van Meerbeek B, Yoshihara K, Yoshida Y, Mine A, De Munck J, Van landuyt KL. State of the art of self-etch adhesives. Dent Mater. 2011;27(1):17-28.

29. Vicente A, Bravo LA. Direct bonding with precoated brackets and self-etching primers. Am J Dent. 2006;19:241-244. 